\title{
Mechanical Characterization and Finite Element Analysis of Jute-Epoxy Composite
}

\author{
Rajole Sangamesh $^{1 *}$, Naveen Kumar ${ }^{1}$, K. S. Ravishankar ${ }^{1}$ and S. M. Kulkarni ${ }^{2}$ \\ ${ }^{1}$ Department of Metallurgical and Materials Engineering, National Institute of Technology \\ Karnataka, India \\ ${ }^{2}$ Department of Mechanical Engineering, National Institute of Technology Karnataka, India
}

\begin{abstract}
Natural fiber composite materials are such an appropriate material, that replaces synthetic composite materials for many of practical applications where we need high strength and low density. Natural fiber composites combine the technological, ecological and economical aspects. This leads to discovering its vast applications in the aeronautics, automotive, marine and sporting sectors. This paper deals with the study on mechanical characterization (Tensile, Compression and Flexural) of jute/epoxy (JE) polymer composite. The flexural properties of composites are experimentally tested and are simulated in commercially available FEA software. Flexural tested results are in good agreement with FEA results. Scanning electron microscopy (SEM) analysis of the failed samples reveals the matrix dominated failure.
\end{abstract}

Keywords: Jute/epoxy composite, Mechanical characterization, FE analysis.

\section{Introduction}

Throughout the 20th and 21st century natural fibers are replacing the existing synthetic fiber because of their better mechanical properties such as stiffness, modulus, and flexibility with respect to glass fibers in the fields of automobile, locomotives, marine structure and commercial application [1,2]. The outstanding preferences of natural fibers are low cost, low density, abundantly available and simple recyclability [3-8]. Jute/epoxy composite is one of the fiber reinforced composites which holds the all the above properties.

Basically, mechanical properties of composite materials depend on the many factors such as the type of matrix and fiber, fiber-length, direction, orientation, weaving patterns and number of layers used in composite [9-12]. Flexural test gives the information about the mechanical properties such as yield stress, ultimate stress, strain, maximum load capability [13].

In recent decades, research progress has occurred based on mechanical properties of natural fiber composite and it is noted that improvement was because of fiber selection, extraction, and treatment $[12,14,15]$. There is scope for modeling of these natural fiber

\footnotetext{
* Corresponding author: rajolesangmesh@gmail.com
} 
composites for a various mechanical testing. From the experiments, it's difficult to analyze the crack initiation and its development in the material which can be easily performed using Finite element analysis software.

The present study addresses the mechanical characterization (tensile, compression and flexural) and flexural simulation of jute/epoxy (JE) polymer composite. Flexural tested and FEA simulated results are compared.

\section{Materials, method and testing}

The Jute/Epoxy composite has been fabricated using woven jute fabric and epoxy (Lapox L-12 with 10\% K-6 hardener). The jute fabric and epoxy resin are used in the ratio of 55\% and $45 \%$ volume fraction respectively. The appropriate quantity of epoxy resin and hardener are mixed in a glass jar using stirrer for a period of 5 minutes. Jute fabric is soaked in the epoxy resin-hardener mixture in order wet the fabric completely. The soacked layers are placed in a square shape steel mold $(300 \times 300 \times 5 \mathrm{~mm})$. Then it covered by a removable plate at above it and that whole system is placed under a compression molding machine with $25 \mathrm{~kg} / \mathrm{cm}^{2}$ constant pressure for more than or equal to 24 hours to cure. The specimen was cut from the manufactured plate using a computerized cutting machine. The geometry of specimens was based on ASTM 3039 for tensile, ASTM 695-02a for compression and ASTM D7264 standards for flexural testing. Specimens were tested in each condition to obtain the properties. The test was carried out using Shimadzu AGX plus $100 \mathrm{KN}$ (Japan) UTM which is shown in Fig. 1(a) for tensile, 1(b) for compression and 1(c) for flexural with a typical arrangement.

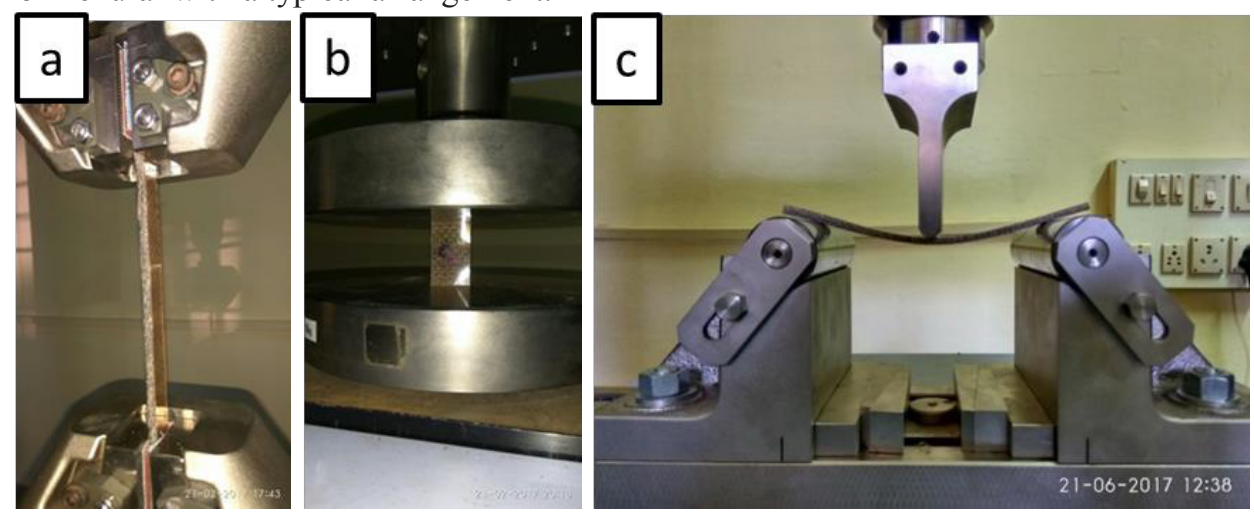

Fig. 1. Testing of samples with fixture for (a) Tensile loading (b) compression loading (c) Flexural loading

These mechanical characterizations have been performed to evaluate the basic properties required for the modeling of these composites so as to validate.

\section{Modeling of jute-epoxy composite for flexural analysis}

FE analysis has been performed to simulate the flexural properties of JE composite which goes as follows:

In CAE "Part Module" JE plate is modeled as Three-dimensional (3D) deformable solid element whereas the support roller and loading rollers are modeled as a $3 \mathrm{D}$ discrete rigid solid element. Density and mechanical properties are defined in CAE "Property Module". These properties are shown in Table 1. JE plate, support roller, and loading rollers are assembled in the "Assembly Module" to perform a flexural simulation as shown in Figure. 2 
(a). In the "Loading Module," the boundary conditions are fixed such that loading roller moves downside (- ve Y direction) and support rollers are fixed in all directions. The meshing of all the parts created using 8 noded linear brick 3D solid element C3D8R in "Mesh Module" which is shown in Fig. 2 (b) and the job is submitted and results are extracted.

Table1 Material properties of Jute/epoxy composite [16]

\begin{tabular}{|l|ll|l|l|l|}
\hline $\begin{array}{l}\text { JE } \\
\text { Composite }\end{array}$ & $\begin{array}{l}\text { Density } \\
\mathrm{kg} / \mathrm{m}^{3}\end{array}$ & $\begin{array}{l}\text { Modulus of elasticity } \\
(\mathrm{E}) \mathrm{GPa}\end{array}$ & $\begin{array}{l}\text { Poisons ratio } \\
(\mathrm{v})\end{array}$ & $\begin{array}{l}\text { Shear Modulus } \\
(\mathrm{G}) \mathrm{GPa}\end{array}$ \\
\hline & $1337.5^{\#}$ & $12.57^{\#}$ & $0.3395^{*}$ & $2.452^{*}$ \\
\hline
\end{tabular}

\# Experiment *Rule of mixture

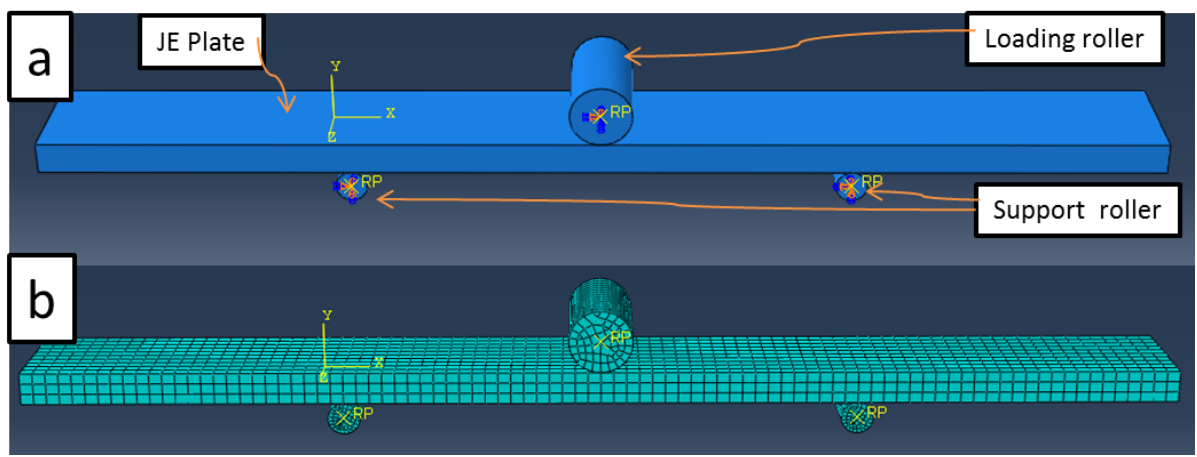

Fig. 2. JE plate flexural loading a) Assembly and b) Mesh of parts

\section{Results and discussion}

The typical experimental stress-strain graph for the jute/epoxy composite is shown in Figure. 3 which proves that JE composites have higher flexural strength than tensile and compression. The tensile strength of the JE composite was found to be $55 \mathrm{MPa}$ which is almost $20 \%$ higher than the woven jute-glass-epoxy hybrid composite characterized by Soma Dalbehera and S. K. Acharya [17]. The compression strength of JE composite was 62 $\mathrm{MPa}$ with failure strain was 0.09 . Whereas the flexural strength of JE was $76 \mathrm{MPa}$ with very less failure strain of 0.015 .
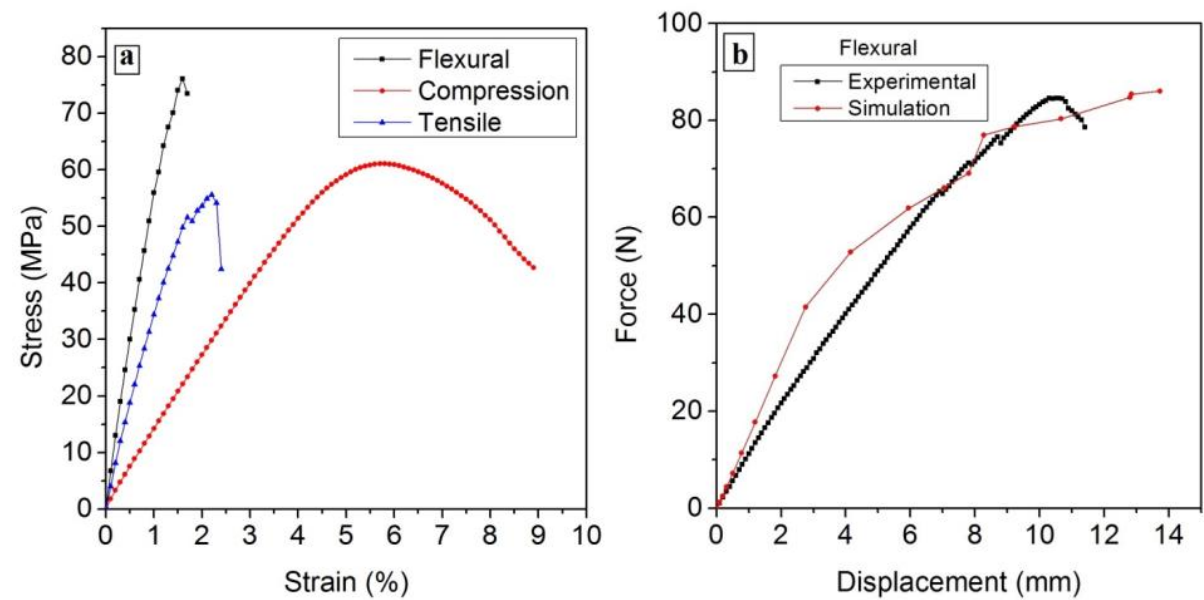

Fig. 3. a) Stress-strain Graph for JE b) Flexural comparison graph of force-displacement curve for JE composite. 
The very similar trend of the force-displacement curve obtained for experimental and simulation is shown in Fig. 3(b). Fig. 4(a) shows simulation at zero seconds and Fig. 4(b) reveals the stress development in the material due to bending thereby very small crack appears on the JE composite which was matrix crack formation. As the bending force increases the development of the crack takes place opposite side of the loading that is bottom side of the plate which can be seen from Fig. 4(c) due to the pulling of the fibers in the opposite direction. On further increasing the load the crack propagates towards the upper side of the plate due to the failure of the jute fibers and finally, failure of component takes place which is seen from the Fig.4 (d). The Fig. 5(a) indicating the matrix dominated failure. Fiber pulls out due to tension at the bottom side of the plate and compression at the top side of the plate. Failed samples which are no more capable of taking the bending load are shown in Fig. 5(b)

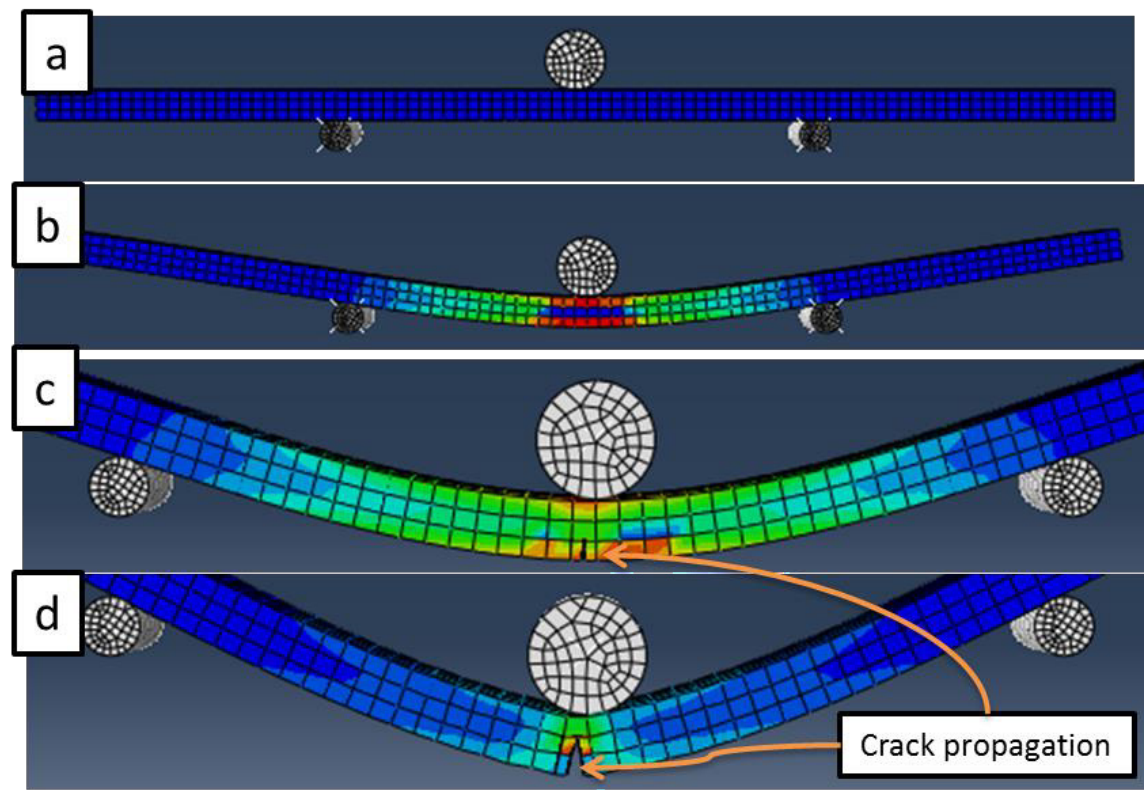

Fig. 4. Flexural simulated stress variation with time for a) $0 \mathrm{~s}$ b) $50 \mathrm{~s}$ c) $70 \mathrm{~s}$ d) $110 \mathrm{~s}$ failed sample

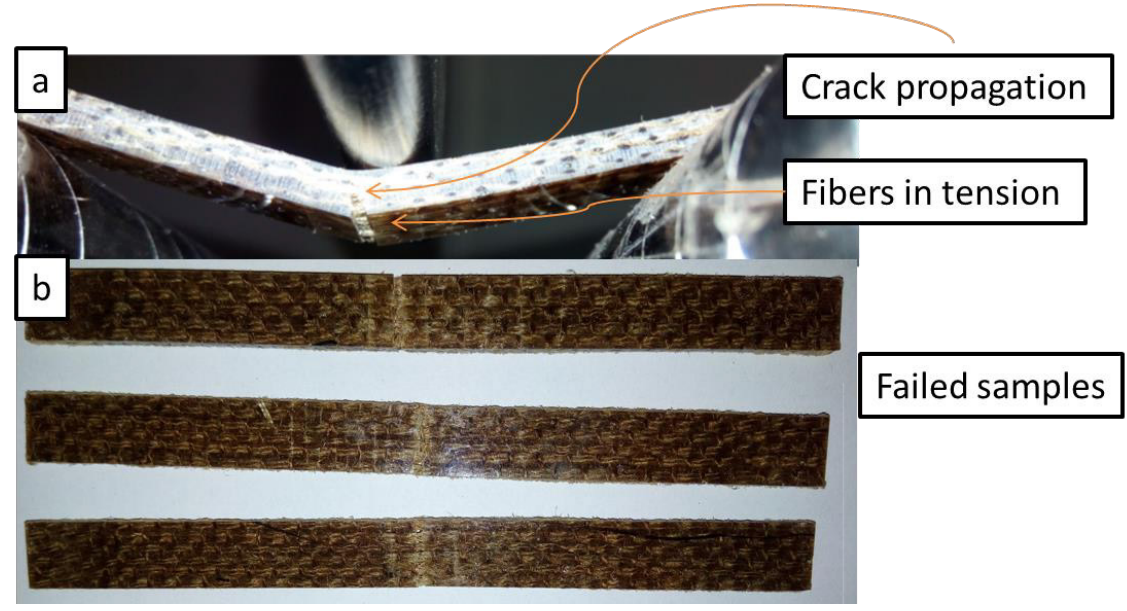

Fig. 5. Experimental JE composite a) Flexural crack propagation and b) Failed sample 
A very similar kind of crack propagation and failure of the bending plate takes place which can be seen from the FE simulation and experimentation plots of Fig. 4(d) and Fig. 5(a) respectively.

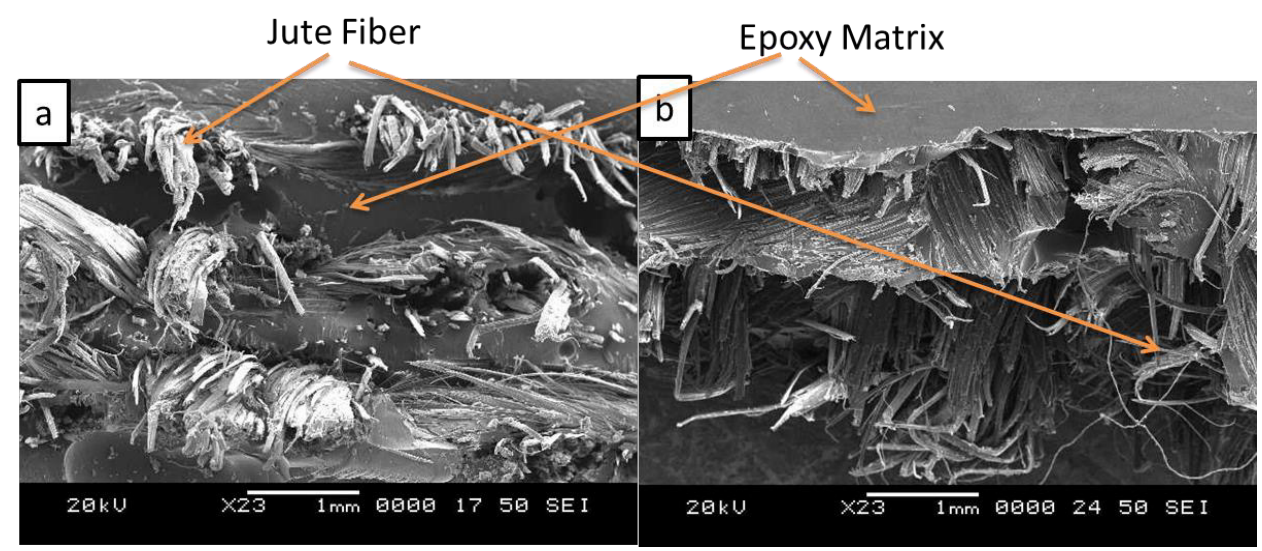

Fig. 6. SEM Fracture micro-graphs of Jute-Epoxy composite

Fig. 6 shows the fracture micro-graph for the jute-epoxy composite flexural tested mixed mode failed specimen, where matrix cracked at the very first with large pulling of fibers, appears on the lower side of the load applied which is very similar to that obtained from the simulation.

\section{Conclusion}

Jute-epoxy composites were fabricated successfully by compression molding technique. Flexural strength of fabricated samples comparatively higher than tensile and compression strength.

The flexural analysis of Jute-epoxy composite has been performed and crack initiation and propagation predicted was very similar to that are obtained from experimental testing.

SEM fractography reveals matrix dominated failure which was also true from the FEA simulation.

\section{References}

1. S. V. Joshi, L. T. Drzal, A. K. Mohanty, \& S. Arora, Composites Part A: Applied science and manufacturing, 35(3), 371-376 (2004)

2. C. W. Chin, \& B. F. Yousif, Wear, 267(9), 1550-1557 (2009)

3. B. F. Yousif, \& H. Ku, Materials \& Design (1980-2015), 36, 847-853 (2012)

4. Z. Leman S. M. Sapuan, M. Azwan, M. M. H. M. Ahmad, \& M. A. Maleque, PolymerPlastics Technology and Engineering, 47(6), 606-612 (2008)

5. U. M. K. Anwar, M. T. Paridah, H. Hamdan, S. M. Sapuan, \& E. S. Bakar, industrial crops and products, 29(1), 214-219 (2009).

6. S. M. Sapuan, M. Harimiand, \& M. A. Maleque, Arabian Journal for Science and Engineering, 28(2), 171-182 (2003)

7. A. A. A. Rashdi, S. M. Sapuan, M. M. H. M. Ahmad, \& A. Khalina, International Journal of Mechanical and Materials Engineering, 5(1) (1970) 
8. M. Jawaid, H.A. Khalil, \& A. A. Bakar, Materials Science, and Engineering: A, 528(15), 5190-5195 (2011)

9. G. Cantero, A. Arbelaiz, R. Llano-Ponte, \&, I. Mondragon, Composites science and technology, 63(9), 1247-1254 (2003)

10. P. Saha, S. Manna, S. R. Chowdhury, R. Sen, D. Roy, \& B. Adhikari, Bioresource technology, 101(9), 3182-3187 (2010)

11. S. Shibata, Y. Cao, \& I. Fukumoto, Composites part A: Applied science and manufacturing, 39(4), 640-646 (2008)

12. V. Vilay, M. Mariatti, R. M. Taib, \& M. Todo, Composites Science and Technology, 68(3), 631-638 (2008)

13. S. Jayabal, \& U. Natarajan, The International Journal of Advanced Manufacturing Technology, 54(5), 639-648 (2011)

14. G. L. S. R. Prasad, M. S. Kumar, \& G. Rajesh, International Journal of Engineering Science Invention, ISSN, 2319-6734 (2014)

15. K. Begum, \& M. Islam, Research J Eng Sci, 2278, 9472. (2013)

16. K. S. Ahmed, \& S. Vijayarangan Indian journal of engineering and material science 13 435-442 (2006)

17. S. D. S. Acharya, Advances in Polymer Science and Technology, 4(1). (2014) 